\title{
$\mathrm{D}$ 형 성격유형, 식생활습관, 환경호르몬 노출위험행위가 월경곤란증에 미치는 영향 \\ 윤 순 정
}

공주대학교 간호학과

\section{Influence of Type D Personality, Dietary Assessment and Increase Exposure Toward Endocrine Disrupting Chemicals on the Dysmenorrhea}

\author{
Soon-Jung Yoon \\ Department of Nursing, Kongju National University
}

\begin{abstract}
Purpose: This study was performed to identify the factors that influence dysmenorrhea.
Methods: In this study, 205 female participants were enrolled. Data were collected using a structured questionnaire that included scales to assess general characteristics, personality type, dietary assessment, eincrease exposure toward endocrine disrupting chemicals, and the occurrence of dysmenorrhea. Data were analyzed using descriptive statistics, $\mathrm{t}$-tests, ANOVA, Pearson's correlational coefficient, and stepwise multiple regression, using the SPSS/WIN 21.0 program.

Results: The average score for dysmenorrhea was $85.04 \pm 32.69$ points. The percentage of participants belonging to the Type D Personality group was $21.0 \%$. Type D Personality $(r=0.473, p<0.001)$ and increase exposure toward endocrine disrupting chemicals $(r=0.532, p<0.001)$ correlated moderately with the level of dysmenorrhea. The correlation between the degree of dietary assessment and the level of dysmenorrhea was weakly negative $(r=$ $-0.170, \mathrm{p}<0.05)$. The most powerful predictor of dysmenorrhea was personality type $(\beta=0.37, \mathrm{p}<0.001)$. A combination of the following factors accounted for $27.3 \%$ of the variance in dysmenorrhea: menstrual amount, menstrual regulation, occupation, and marital status.
\end{abstract}

Conclusions: The results indicate that when nursing assessments and interventions are performed for women with dysmenorrhea, it is necessary for nurses to take into account the personality type of the patient.

Key Words: type D personality, dysmenorrhea

\section{서 론}

교신저자: 윤순정, 충청남도 공주시 공주대학로 56

공주대학교 간호학과

전화번호: 041-850-0300, 팩스번호: 041-850-0315

E-mail: k67651471@gmail.com

접수일자: 2017년 10월 31일, 심사일자: 2017년 12월 12일

게재확정일자: 2018년 12월 15일

Copyright (c) 2018 by The Korean Society of Maternal and Child Health

\section{1. 연구의 배경}

월경은 가임기 여성의 증표로써 건강상태를 반영하는 주기 를 갖는 정상적인 생리현상이며, 여성의 일생을 통해 자연스 럽게 경험하게 되는 과정이다. 하지만 안타깝게도 그 과정은 피할 수 없는 불편함을 동반하게 되어, 많은 여성이 월경 시 불편감으로 인해 신체적, 정신적, 정서적, 사회적인 영향을 받 게 된다(Kim, 2011). 월경의 주기나 양에서 변화를 초래하거 
Yoon SJ. Influence of Type D Personality, Dietary Assessment and Increase Exposure Toward Endocrine Disrupting Chemicals on the Dysmenorrhea

나 통증을 동반하는 경우를 포괄적으로 월경장애라 표현하는 데, 이때 통증을 동반한 월경을 월경곤란증 (dysmenorrhea) 이라 한다(WHNAR, 2012). 골반의 기질적인 병변 유무에 따라 속발성 월경곤란증과 원발성 월경곤란증으로 구분하며 (WHNAR, 2012), 증상은 월경이 시작하기 직전이나 시작할 때 나타나고 월경이 끝나기 전에 없어진다(NIKL, 2017a). 월 경곤란증은 전체 여성의 $80 \%$ 가 불편감을 보이고 전체의 10 $\%$ 는 심한 통증을 나타내어(WHNAR, 2012), 여성이라는 주 체에 불편함과 불쾌감을 주게 된다.

월경곤란증의 원인과 관련된 연구는 그동안 증상의 원인과 관련한 일부 연령대 및 특정 직업군에 대한 연구나(Park et al., 2012; Kim et al., 2013; Hwang \& Sung, 2016; Han et al., 2017), 환경오염물질과 윌경과의 관련성 연구처럼 (Mendola et al., 2008) 연구대상자를 둘러싸고 있는 외적인 요인과의 관련성에 대해 많은 연구가 이루어져왔다. 하지만 본 연구자는 좀 더 대상자 개인의 요인에 집중한 연구를 진행하 고자, 대상자가 어떠한 개인적 성격양상을 보이고, 음식을 먹 고, 어떠한 환경에서 사느냐를 중요 변수로 연구하고자 한다.

개인의 성향을 나타내는 대표적인 것이 성격유형이라 할 수 있다. 성격이라는 것은 개인이 가지고 있는 고유의 성질이나 품성으로 정의되며(NIKL, 2017b), 한 사람의 일생을 좌우하 는 결정적 요인이 되기도 한다. 본 연구에서 나타내는 D 성격 유형은 질환관련성 연구(Denollet \& Van Heck, 2001)나 스 트레스 관련 연구(Kim et al., 2014) 등에 널리 사용되는 개 념이다. "Distressed"를 나타내는 D를 약어로 사용하며, 부정 적 정서와 사회적 억제의 두 개념으로 구성된 성격 유형으로, 우울하고, 불안하고, 사회적으로 부적절하게 근심과 걱정이 많 은 것을 특징으로 한다(Denollet \& Van Heck, 2001).

기본적으로 사람의 의식주는 사람의 몸에 필연적으로 영향 을 주게 된다. 이와 관련하여 의식주 관련 사항을 모두 포함한 다고 판단되는 변수로 환경호르몬 노출위험행위라는 변수를 선택했고, 의식주 중 먹는 것의 중요성과 선행연구를 고려하여 식생활 습관을 추가 변수로 연구하였다. 선행연구에 따르면 식생활 습관의 변화는 스트레스와 우울감에도 영향을 주는 것 으로 나타났으며(Kim et al., 2014), 식사의 개선은 적당한 운동의 권장, 증상에 따른 대증요법의 적용과 더불어 현재 월 경곤란증의 중요 간호중재 요인이기도 하다(WHNAR, 2012).

월경곤란증에 대한 선행연구들은 앞서 언급한 연구들 외에 월경곤란증 원인 관련 연구로 식습관, 생활습관 및 친환경 행 위 등에 대한 연구 등(Lee et al., 2010; Kim, 2011)이 있고,
월경곤란증의 중재효과를 확인하기 위한 연구들과 관련해서 는 관련 연구들을 종합한 월경 불편감 보완 대체 중재효과에 대한 메타분석이 이루어지기도 하였다(Kim et al., 2013). 하 지만 월경이 일정 연령과 직업에만 나타나는 증상이 아님을 생각해 보면 다양한 연령대와 폭넓은 직업군을 대상으로 하는 연구 또한 필요하고, 이들을 포괄적으로 포함하는 원인에 대 한 분석이 필요하다.

이에 본 연구자는 모든 연구의 시작은 개인에 대한 기본적 인 이해에 바탕을 두어야 한다는 판단에 따라 여성으로서 피 할 수 없는 월경이라는 손님과 그로인한 불편함과 곤란증은 그를 대하는 여성 개인의 원천적인 태도인 성격의 영향을 받 을 것이라 판단하였다. 이를 확인하기 위해 개인의 기본적인 성향이 확립되고, 한국에서 대학에 입학하는 만 18 세 이상부 터 폐경전까지의 다양한 여성들을 대상으로 개인의 성격과 생 활을 중심으로 한 월경곤란증 관련 연구를 진행하고, 이를 월 경곤란증 관련 여성건강간호를 위한 간호중재개발 및 간호정 책 관련 연구에 기초자료로 제공하고자 한다.

\section{2. 연구 목적}

본 연구의 구체적인 목적은 다음과 같다.

1) 연구대상자의 일반적 특성에 따른 월경곤란증의 차이를 파악한다.

2) 연구대상자의 성격유형, 식생활습관, 환경호르몬 노출위 험행위, 월경곤란증 정도를 파악한다.

3) 연구대상자의 성격유형, 식생활습관, 환경호르몬 노출위 험행위와 월경곤란증의 관련성을 파악한다.

4) 연구대상자의 월경곤란증에 영향을 미치는 요인을 파악 한다.

\section{연구대상 및 방법}

\section{1. 연구 설계 및 대상}

본 연구는 가임 여성의 성격, 식생활습관, 환경호르몬노출 위험행위와 월경곤란증과의 상관성을 파악하고 월경곤란증 영향요인을 밝힘으로써 월경곤란증 관련 간호중재 개발을 위 한 기초자료를 제공하기 위한 서술적 상관성 조사연구이다.

본 연구는 18 세 이상에서 폐경전까지의 가임 여성 중 골반 에 기질적 병변이 없는 여성을 대상자로 선정하였다. 최소 연 
령 18세는 한국에서 대학에 진학하는 일반적인 나이로 성격 및 식생활습관에 대한 형성과 생활양식의 자발적 선택 가능 시기 를 고려하였으며, 초경 2년 후에 나타나는 월경곤란증은 속발 성 월경곤란증으로 보는 선행 연구를 고려하였다(WHNAR, 2012).

본 연구의 자료수집은 본 연구자와 자료 수집 방법에 대해 교육받은 연구보조원 1 인이 $\mathrm{S}$ 시 $\mathrm{N}$ 구의 지역사회에서 자료를 수집하였으며, 수집 장소는 지역사회 커뮤니티 모임을 통한 눈덩이 표집방식과 도서관 및 학교, 종교단체의 자조모임 참 여자 등을 통해 자발적으로 이루어졌다. 자료 수집자 간의 측 정오차를 줄이기 위해 사전교육과 회의를 3 차에 걸쳐 시도하 였고, 도구의 문항과 내용을 충분히 숙지하여 참여자의 질문 에 대한 설명내용을 동일하게 유지하도록 하였다.

연구를 위한 표본 수는 $\mathrm{G} *$ power 3.1 .7 프로그램을 이용하 여 계산되었으며, 유의수준 0.05 , 효과크기 0.15, power 0.95 로 계산하였을 때 탈락률을 고려한 총 표본 수는 209개였으 며, 최소 표본수는 183개로 산출되었다(Faul et al., 2009). 최종적으로 본 연구에 사용된 대상자 수는 205명으로 적절하 였다.

\section{2. 연구도구}

\section{1) 성격유형 (Personality)}

사용된 D 성격유형 관련 도구는 Denollet (2005)가 개발 한 D유형 성격 측정도구 DS14 (the Type D Scale-14)를 Son (2008)이 한국어로 번역하여 타당도와 신뢰도를 검증한 도구를 사용하였다. 총 14 문항, Likert 5 점 척도로 '아니다' 0 점에서 '그렇다' 4 점으로 구성되어, 부정적 정서 7 문항과 사회 적 억제 7문항의 2개 하부영역으로 구성되었다. DS14는 하부 영역 각각의 점수가 모두 10 점 이상일 때 $\mathrm{D}$ 유형 성격으로 분 류된다. Son (2008) 의 연구에서 도구의 신뢰도 Cronbach's alpha는 0.79 이며, 본 연구에서는 0.93 이었다.

\section{2) 식생활습관(Dietary Assessment)}

전반적인 식생활의 질은 $\mathrm{Kim}$ 등(2003)이 개발한 간이 식 생활 진단표(Mini Dietary Assesment Index, MDA)를 이용 하여 평가하였다. $\mathrm{MDA}$ 도구는 일반인의 식사의 질을 간단하 게 평가할 수 있는 도구로 타당성이 검증되었으며, '항상 그렇 다' 5 점에서 '보통이다' 3 점, '아니다' 1점으로 점수화 된다. 3 개의 하부영역은 충분한 섭취 권장과 관련된 4 문항, 과잉섭취
를 줄이도록 권장하는 4 문항, 균형잡힌 식생활과 관련된 2 문 항이며, 총 10 문항에 50 점 만점으로 구성되어있다. $\mathrm{MDA}$ 는 합산 점수가 높을수록 식생활의 질이 높음을 의미한다.

3) 환경호르몬 노출위험행위(Increase Exposure toward Endocrine Disrupting Chemicals)

환경호르몬의 잠재적 위험에 대한 노출 위험행위가 일상생 활에서 얼마나 이루어지는지를 보는 것으로 $\mathrm{Kim}$ 과 $\mathrm{Kim}$ (2009)이 환경호르몬 노출저감화 행동 측정도구를 개발한 것 을 토대로 Cheon 등(2016)이 사용한 도구를 사용하였다. 총 23문항이며, Likert 5 점 척도로 각 문항은 '전혀 그렇지 않다' 1점에서 '매우 그렇다' 5 점으로 구성되었다. 긍정적인 문항은 역코딩하였고 점수가 높을수록 환경호르몬 노출 위험행위정 도가 높음을 의미한다. 개발 당시의 신뢰도 Cronbach's alpha 는 0.83 이며, 본 연구에서는 0.80 였다.

\section{4) 월경곤란증(Dysmenorrhea)}

Moos (1968)가 개발한 Menstrual Distress Questionnaire (MDQ)를 $\operatorname{Kim}$ (1995)이 수정한 설문지로 측정하였다. Likert 6점 척도로 각 문항은 '전혀 없다' 1점에서 '아주 심하 다 6 점으로 구성되었으며, 6 개의 하부영역으로 신체적 통증 6 문항, 집중력 저하 8 문항, 행동변화 5 문항, 자율신경계반응 4 문항, 수분축적 4 문항, 부정적 정서 8 문항의 총 35 문항이다. 전체 점수는 35 점에서 210 점의 범위를 가지고 있고, 점수가 높을수록 월경곤란증이 심하다는 것을 의미한다. 신뢰도 Cronbach's alpha는 Kim (1995)의 연구에서 0.97이며, 본 연구에서도 0.97 이었다.

\section{3. 자료수집 방법과 윤리적 고려}

골반의 기질적인 병변이 없는 각 대상자에게 연구목적을 설 명한 뒤 참여를 희망하는 경우 서면동의 후 구조화된 설문지 를 이용하였다. 설문지는 대상자가 직접 기입하였으며 214 부 의 설문지 중 응답이 불완전한 설문지 9 부를 제외한 후 최종 205 부를 분석에 이용하였다. 자료수집기간은 2017년 6월 23 일부터 7 월 6일까지였다.

연구에 앞서 연구자가 소속된 대학의 임상심의위원회(Institutional Review Board, IRB) 에서 연구내용, 연구절차, 피 험자 설명문, 동의서 및 설문지에 관한 내용에 대하여 심의 절 차를 거쳐 승인 후 연구를 진행하였다(IRB No. KNU_IRB_ 
Yoon SJ. Influence of Type D Personality, Dietary Assessment and Increase Exposure Toward Endocrine Disrupting Chemicals on the Dysmenorrhea

2017-28). 연구 대상자에게는 연구 목적과 취지를 설명하였 고, 연구를 통해 알게 된 내용은 연구 목적만을 위해 사용할 것이며, 연구 참여자의 익명이 보장됨을 설명 및 기재하였다. 또한 연구 참여는 본인의 자율적 의사를 충분히 반영하였고, 중간에 원치 않을 경우 중단할 수 있음과 추후 언제든지 문의 사항이 있을 경우 연락할 수 있도록 연락처를 알렸으며, 연구 참여에 대한 감사의 사례를 하였다.

\section{4. 자료분석}

수집된 자료는 IBM SPSS 프로그램(Windows, Ver.21.0, SPSS Inc., Chicago, IL, USA)을 이용하여 전산통계 처리하 였으며, 자료 분석 방법은 다음과 같다.

1) 연구대상자 일반적 특성은 기술통계 및 빈도분석을 사 용하였다.

2) 연구대상자의 성격유형, 식생활습관, 환경호르몬 노출 위험행위, 월경곤란증 정도는 평균과 표준편차로 구하였다.

3) 연구대상자의 일반적 특성에 따른 월경곤란증 정도 차이 는 t-test와 ANOVA, 사후검정은 Scheffé test로 하였다.

4) 연구대상자의 성격유형, 식생활습관, 환경호르몬 노출위 험행위, 월경곤란증과의 상관관계는 Pearson's Correlation Coefficient로 분석하였다.

5) 연구 대상자의 월경곤란증 영향요인은 월경곤란증과 통 계적으로 유의한 차이를 보인 요인을 통제한 상태에서 단계적 다중회귀분석을 실시하였다.

\section{성 적}

\section{1. 대상자의 일반적 특성}

본 연구대상자의 평균연령은 34.01 ( \pm 7.37$)$ 세로 31 40세 가 $51.7 \%$ 로 가장 많았으며, 초경시작 연령은 평균 $13.6( \pm$ 1.41)세였다. 교육정도는 대졸이 $77.6 \%$ 로 가장 많았고 고졸 이하와 대학원졸 이상의 순이었다. 대상자의 $65.4 \%$ 는 기혼이 었으며, 기혼여성 중 $85.1 \%$ 가 출산경험이 있었다. 직업은 근 로자가 $68.8 \%$ 로 가장 많았고 그 뒤로 주부, 학생의 순이었으 며, 대상자의 $90.7 \%$ 는 보통수준의 경제상태라 응답하였다. 월 경간격은 $69.8 \%$ 가 규칙적이었고, 월경양은 $62.9 \%$ 가 보통정 도였으며, 생리대는 화학생리대만 사용하는 사람이 $91.7 \%$ 였 다(Table 1).

\section{2. 연구대상자의 성격유형, 식생활습관, 환경호르몬 노출 위험행위, 월경시 통증과 월경곤란증 정도}

연구대상자 중 $21.0 \%$ (43명)가 D형 성격유형을 나타냈으 며, 이들의 부정적 정서는 평균 15.09 ( \pm 4.02$)$, 사회적 제한 은 평균 14.60 ( \pm 3.58 ) 점이었다. 식생활습관은 평균 32.37 ( \pm 5.93$)$ 점, 환경호르몬 노출위험행위는 평균 55.13 ( \pm 10.94$)$ 점, 월경곤란증은 평균 85.04 ( \pm 32.69$)$ 점을 나타냈다(Table 2).

\section{3. 연구대상자의 성격유형, 식생활습관, 환경호르몬 노출 위험행위, 월경곤란증의 상관관계}

상관관계 결과 월경곤란증은 $\mathrm{D}$ 형 성격유형 $(\mathrm{r}=0.473, \mathrm{p}<$ $0.001)$, 환경호르몬 노출위험행위 $(r=0.213, p<0.001)$ 와 순 상관관계, 식생활습관 $(\mathrm{r}=-0.170, \mathrm{p}<0.05)$ 과 역상관관계를 나타내었다. 즉, 성격이 $\mathrm{D}$ 형 성격유형을 나타내면서 환경호르 몬 노출위험행위가 많고, 식생활 습관이 나쁠수록 월경곤란증 이 컸다(Table 3 ).

\section{4. 월경곤란증에 영향을 미치는 요인}

가임 여성의 월경곤란증 영향요인을 파악하기 위해 통계적 으로 유의한 차이를 보인 변수들을 대상으로 단계적 다중회귀 분석을 실시하였다. 관련성을 나타낸 일반적 특성의 변수로는 연령, 결혼여부, 직업종류, 월경간격 규칙성과 월경양이며, 주 요 독립 변수 중 성격유형, 식생활 습관, 환경호르몬 노출위험 행위였다. 이 중 명목척도 형태의 결혼여부, 직업종류, 월경의 규칙성은 Dummy 변수 처리하였다. 분석 이전에 조사한 다중 공선성 검정에서는 공차가 $0.83 \sim 0.96$, 분산팽창계수(Variance inflation factor, VIF) 값은 1.04 1.21로 나타나 모든 변수에서 다중공선성의 문제는 없었다. 회귀분석 결과, 성격 유형 $(\beta=0.37, p<0.001)$, 월경양 $(\beta=0.22, p<0.001)$, 직업종 류 $(\beta=0.17, p=0.010)$, 결혼여부 $(\beta=-0.24, p<0.001)$, 월 경간격 규칙성 $(\beta=-0.13, p=0.042)$ 이 통계적으로 유의한 영 향변인으로 나타났다. 성격유형, 월경양, 직업종류, 결혼여부, 월경간격의 5 가지 변인은 연구대상자 월경곤란증의 $27.3 \%$ 를 설명하였으며. 그 중 $\mathrm{D}$ 형 성격유형의 설명력은 $17.7 \%$ 로 월경 곤란증 관련 가장 강력한 영향요인으로 나타났다(Table 4). 
Table 1. Difference of Dysmenorrhea according to General Characteristics

$(\mathrm{N}=205)$

\begin{tabular}{|c|c|c|c|c|c|}
\hline \multirow{2}{*}{ Characteristics } & \multirow{2}{*}{ Categories } & \multirow{2}{*}{$\mathrm{n}(\%)$} & \multicolumn{3}{|c|}{ Difference of Dysmenorrhea } \\
\hline & & & $\mathrm{M} \pm \mathrm{SD}$ & $\mathrm{t}$ or $\mathrm{F}$ & $\mathrm{p}$ (Scheffe) \\
\hline \multirow[t]{3}{*}{ Age (years) } & $\leq 30^{\mathrm{a}}$ & $60(29.3)$ & $97.13 \pm 35.80$ & 7.290 & 0.001 \\
\hline & $31 \sim 40^{\mathrm{b}}$ & $106(51.7)$ & $82.44 \pm 30.18$ & & $(a>b, c)$ \\
\hline & $\geq 41^{\mathrm{c}}$ & $39(19.0)$ & $73.51 \pm 29.03$ & & \\
\hline Menarche age (years) & & $205(100)$ & $13.60 \pm 1.41$ & & \\
\hline \multirow{3}{*}{ Education level } & $\leq$ High School & $34(16.6)$ & $95.06 \pm 39.80$ & 2.128 & 0.122 \\
\hline & University & $159(77.6)$ & $83.48 \pm 30.39$ & & \\
\hline & $\geq$ Graduate & $12(5.9)$ & $77.42 \pm 37.31$ & & \\
\hline \multirow[t]{2}{*}{ Marital status } & Single & $71(34.6)$ & $93.82 \pm 36.17$ & 2.682 & 0.008 \\
\hline & Married & $134(65.4)$ & $80.40 \pm 29.78$ & & \\
\hline \multirow[t]{2}{*}{ Childbirth (Only married) } & Yes & $114(85.1)$ & $80.41 \pm 30.23$ & 0.015 & 0.988 \\
\hline & No & $20(14.9)$ & $80.30 \pm 27.81$ & & \\
\hline \multirow[t]{3}{*}{ Occupation } & Student $\mathrm{t}^{\mathrm{a}}$ & $22(10.7)$ & $101.77 \pm 40.30$ & 4.598 & 0.011 \\
\hline & Homemaker ${ }^{\mathrm{b}}$ & $42(20.5)$ & $89.93 \pm 31.17$ & & $(a>c)$ \\
\hline & Worker $^{c}$ & $141(68.8)$ & $80.98 \pm 31.00$ & & \\
\hline \multirow[t]{3}{*}{ Economic status } & Low & $13(6.3)$ & $92.31 \pm 37.17$ & 0.358 & 0.700 \\
\hline & Middle & $186(90.7)$ & $84.47 \pm 31.98$ & & \\
\hline & High & $6(2.9)$ & $87.00 \pm 47.64$ & & \\
\hline \multirow[t]{2}{*}{ Menstrual regulation } & Irregular & $62(30.2)$ & $94.79 \pm 38.00$ & 2.583 & 0.011 \\
\hline & Regular & $143(69.8)$ & $80.82 \pm 29.24$ & & \\
\hline \multirow[t]{3}{*}{ Menstrual amount } & Small $^{\mathrm{a}}$ & $37(18.0)$ & $70.41 \pm 26.63$ & 5.910 & 0.003 \\
\hline & Medium $^{\mathrm{b}}$ & $129(62.9)$ & $86.20 \pm 32.74$ & & $(a>b, c)$ \\
\hline & Large $^{c}$ & 39 (19.0) & $95.10 \pm 33.71$ & & \\
\hline \multirow[t]{2}{*}{ Menstural pad } & Cloth pad & $17(8.3)$ & $80.59 \pm 27.20$ & -0.586 & 0.559 \\
\hline & Chemical pad & $188(91.7)$ & $85.45 \pm 33.17$ & & \\
\hline
\end{tabular}

Table 2. Degree of Type D Personality, Dietary Assessment, Increase Exposure toward EDCs and Dysmenorrhea

\begin{tabular}{lcccc}
\hline Variables & $\mathrm{N}(\%)$ & $\mathrm{M} \pm \mathrm{SD}$ & Possible range & Actual range \\
\hline Type D Personality & & & & \\
$\quad$ Non-Type D & & & & \\
$\quad$ Negative affectivity & $162(79.0)$ & $4.96 \pm 3.96$ & $0 \sim 28$ & $0 \sim 18$ \\
$\quad$ & & & $0 \sim 28$ & $0 \sim 18$ \\
$\quad$ Social inhibition & & $15.09 \pm 4.02$ & $0 \sim 28$ & $10 \sim 24$ \\
$\quad$ Type D & $43(21.0)$ & $14.60 \pm 3.58$ & $0 \sim 28$ & $10 \sim 24$ \\
$\quad$ Negative affectivity & $205(100)$ & $32.37 \pm 5.93$ & $10 \sim 50$ & $17 \sim 47$ \\
$\quad$ Social inhibition & $205(100)$ & $55.13 \pm 10.94$ & $23 \sim 115$ & $31 \sim 91$ \\
Dietary Assessment & $205(100)$ & $85.04 \pm 32.69$ & $35 \sim 210$ & $37 \sim 179$ \\
Increase Exposure toward EDCs & & & \\
Dysmenorrhea &
\end{tabular}

Abbreviation: EDCs, endocrine disrupting chemicals.

\section{고 찰}

본 연구는 가임기 여성의 월경곤란증 정도를 알아보고 월경 곤란증 관련변수로 성격유형과 식생활 습관 및 환경호르몬 노 출위험행위를 설정하여 각 변수가 월경곤란증에 미치는 영향
에 대하여 알아보았으며, 그 결과에 대해 다음과 같이 논의하 고자 한다.

연구대상자의 월경곤란증 점수는 평균 85.04점으로 동일 도구를 사용한 $\operatorname{Kim}$ (2011)의 81.2점과 큰 차이를 나타내지 않았다. 일반적 특성에 따른 월경곤란증 차이를 분석한 결과, 
Yoon SJ. Influence of Type D Personality, Dietary Assessment and Increase Exposure Toward Endocrine Disrupting Chemicals on the Dysmenorrhea

Table 3. Correlation among Personality, Dietary Assessment, Increase Exposure toward EDCs and Dysmenorrhea

\begin{tabular}{lcccc}
\hline Variables & $\begin{array}{c}\text { Personality } \\
\mathrm{r}(\mathrm{p})\end{array}$ & $\begin{array}{c}\text { Dietary Assessment } \\
\mathrm{r}(\mathrm{p})\end{array}$ & $\begin{array}{c}\text { Increase Exposure toward EDCs } \\
\mathrm{r}(\mathrm{p})\end{array}$ & $\begin{array}{c}\text { Dysmenorrhea } \\
\mathrm{r}(\mathrm{p})\end{array}$ \\
\hline Personality & 1 & & & \\
Dietary Assessment & $-0.095(0.167)$ & 1 & 1 & \\
Increase Exposure toward EDCs & $0.232(0.001)$ & $-0.360(<0.001)$ & $0.213(0.002)$ & 1 \\
Dysmenorrhea & $0.473(<0.001)$ & $-0.170(0.013)$ & \\
\hline
\end{tabular}

Abbreviation: EDCs, endocrine disrupting chemicals.

Table 4. Multiple Regression Analysis for Risk Factors associated with Dysmenorrhea

\begin{tabular}{lccrrrrrrr}
\hline Variables & $\mathrm{B}$ & $\mathrm{SE}$ & $\mathrm{B}$ & $\mathrm{t}$ & $\mathrm{p}$ & Adjusted $\mathrm{R}^{2}$ & $\mathrm{~F}$ & $\mathrm{p}$ & $\mathrm{VIF}$ \\
\hline (Constant) & 40.20 & 9.25 & & 4.35 & $<0.001$ & & & & \\
Personality & 29.47 & 4.88 & 0.37 & 6.04 & $<0.001$ & 0.177 & 44.99 & $<0.001$ & 1.04 \\
Menstrual amount & 11.62 & 3.26 & 0.22 & 3.56 & $<0.001$ & 0.241 & 8.61 & 0.004 & 1.04 \\
Occupation & 13.65 & 5.22 & 0.17 & 2.61 & 0.010 & 0.252 & 4.15 & 0.043 & 1.17 \\
Marital status & -16.61 & 4.49 & -0.24 & -3.70 & $<0.001$ & 0.261 & 2.52 & 0.115 & 1.21 \\
Menstrual regulation & -8.85 & 4.32 & -0.13 & -2.05 & 0.042 & 0.273 & 4.20 & 0.042 & 1.04
\end{tabular}

Dummy Coded: marital status, occupation, menstrual regulation.

월경곤란증은 연령, 결혼여부, 직업종류, 월경간격 규칙성과 월 경양에 유의미한 차이를 나타냈다. 연구에서 연령, 결혼여부, 직업과의 유의미성은 $\operatorname{Kim}$ (2011)의 연구와도 같은 결과인 데, 본 연구에서 20 대, 미혼, 학생의 월결곤란증이 높게 나온 것은 모두 연령과 관련된 부분으로 판단된다. 관련연구에 따 르면 월경곤란증에 따른 불편감은 20 대 여성이 가장 많이 경 험하는 것으로 나타나는데(WHNAR, 2012), 20대의 여성은 학생이고 미혼일 확률이 그렇지 않을 확률보다 크기 때문이다. 월경간격이 규칙적이고 월경양이 적은 경우 월경곤란증이 적 게 나타났는데, 월경양에 따른 차이는 Jung 등(2014)의 연구 와 같은 결과를 나타냈으며, 규칙적이고 적당한 월경양은 일 부 건강성 정도와 관련된 것으로 판단된다.

선택한 독립변수와의 관련성에서는 성격유형, 식생활습관 및 환경호르몬 노출위험행위 모두 유의미한 상관관계를 나타 냈다. 대상자 $21 \%$ 가 D형 성격유형으로 나타난 것은 $\operatorname{Lim}$ 등 (2011)이 한국어판 DS14의 타당도 연구시 27.8\%가 D형 성 격유형으로 나타난 것과 비교하면 다소 낮은 수준이다. 이것 은 대상자의 차이에 따른 결과로 보여지는데, 동일 도구를 간 호사에게 적용한 $\operatorname{Kim}$ 등(2014)의 연구에서는 $79.7 \%$ 가 D형 성격유형으로 나타나기도 하여 $\mathrm{D}$ 형 성격유형은 직업형태와 질 환여부 등 대상자 특성에 따라 빈도적 차이가 발생하는 것으 로 보인다. 본 연구의 대상자들은 성별에 있어서 여성으로 한 정 되었지만, 다양한 직업군과 연령대로 구성되고 특이질환을 보유하지 않은 건강군이라는 등의 특징이 반영되었다고 판단
된다. 월경곤란증과 $\mathrm{D}$ 형 성격유형이 관련성을 보인 것은, 월경 에 대한 태도가 부정적일수록 월경전증후군이 심하게 나타났 다는 연구를 통해 봤을 때(Guvenc et al., 2012; Han et al., 2017), 근심과 걱정이 많은 것을 특성으로 하는 D형 성격유 형 대상자들의 부정적인 태도가 반영된 것으로 보인다. 또한 선행연구들을 통해 확인할 수 있는 $\mathrm{D}$ 형 성격유형의 질환관련 성 특징들이나(Denollet \& Van Heck, 2001; Son et al., 2012), Bae 등(2011)의 연구에서 D유형 성격을 가진 대상 자는 $\mathrm{D}$ 유형 성격이 아닌 대상자보다 신체적, 정신적 건강상태 를 낮게 보고하였다는 것과도 같은 방향을 나타낸다고 판단된 다.

식생활습관 평균 32.37점은 $\mathrm{Kim}$ 등(2003)의 도구 개발 당 시의 연구에서 여성대상자가 31.89점을 나타낸 것과 큰 차이 를 나타내지 않았다. 미세한 상승에 대해서는 주부집단이 포 함된 연구대상자의 차이나 참살이(Well-being) 가 강조되는 연구시점의 차이가 반영되었을 것으로 사료된다.

환경호르몬 노출위험행위는 평균 55.13점으로 Cheon 등 (2016)이 동일도구로 대학생을 대상으로 한 연구에서 평균 61.57 점을 나타낸 것과 비교하여 본 연구의 대상자들이 상대 적으로 환경호르몬 노출위험행위를 적게 하는 것을 의미하는 것으로, Cheon 등(2016)의 연구가 대학생만을 대상으로 하 고 남성이 포함된 것과 비교하여 여성만으로 구성되어 있으며, 연령 분포에서 가족의 건강을 챙기는 주부의 집단까지 광범위 하게 구성되어있는 등의 이유가 영향을 미쳤을 것으로 판단된 
다. 환경호르몬 노출위험행위가 높을수록 월경곤란증이 증가 하는 순상관관계는 대안생리대의 사용을 친환경행위로 설정 하여 연구한 Kim (2011)의 연구에서 친환경행위가 월경곤란 증 점수에서 유의한 차이를 나타냈던 것과 같은 방향성을 나 타낸다. 본 연구에서의 환경호르몬 노출위험행위는 친환경행 위에 반대되는 개념이자 의식주 전체에 걸친 행위와 관련되어 월경곤란증에 있어 의식주의 중요성을 나타낸다고도 사료된다.

본 연구의 설명력 $27.3 \%$ 는 Jung 등(2014)의 연구 $27 \%$ 와 비슷한 결과다. $\mathrm{D}$ 형 성격유형의 설명력은 $17.7 \%$ 로 월경곤란 증 관련 가장 강력한 영향요인이었다. Jung 등(2014)의 연구 에서는 월경에 대한 태도와 스트레스가 월경전증후군의 영향 요인이었는데, 어떠한 태도와 스트레스는 개인의 성향과 밀접 한 관계가 있음을 상기할 때 본 연구결과와 맥을 같이한다고 판단된다. 이와 관련하여 대상을 바라보는 태도와 삶의 여러 가지 스트레스는 성격과 밀접한 관련성 있고, 선행연구들에 따르면 성격특성은 스트레스와 관련이 있었다(Kim et al., 2014; Yoon et al., 2014).

본 연구결과는 일부 한정된 지역에서 진행되어 연구결과를 일반화함에 있어 주의가 필요하다. 하지만 기존 월경곤란증 관련 연구가 주로 월경 불편감 보완 대체 중재효과에 대한 연 구가 많고, 인간 개인 특성에 대한 접근이 많지 않았음을 감안 했을 때, 본 연구는 인간 개인의 특성에 중점을 두어 간호전략 적으로 여성의 월경곤란증 관련 성격유형에 대한 분석과 분류 를 통한 접근의 필요성을 밝혔다는데 의의가 있다.

본 연구 결과를 토대로 가임여성들의 월경곤란증 감소를 위 해 기존의 간호중재 프로그램에 더해 필요시 성격유형에 따라 명상요법 등을 활용한 성격적 차분함을 유도하는 프로그램 및 기존의 식사 프로그램의 개선 등과 관련하여 환경호르몬 노출 위험행위를 감소시킬 수 있는 방향으로의 유도 프로그램 등을 제언한다.

\section{결 론}

본 연구는 가임기 여성의 월경곤란증 정도를 알아보고, 성 격유형, 식생활습관, 환경호르몬 노출위험행위의 월경곤란증 과의 상관관계 및 영향력을 확인하는 연구이다. 본 연구의 주 요 결과는 다음과 같다.

연구대상자의 월경곤란증 정도는 평균 85.04점이었으며, 월경곤란증과 제 변수간의 상관관계를 분석한 결과, 성격이 D 형 성격유형을 나타내면서 환경호르몬 노출위험행위가 많고,
식생활 습관이 나쁠수록 월경곤란증이 컸다. 또한 연구대상자 의 월경곤란증을 설명하는 유의한 변수는 성격유형, 월경양, 직업종류, 결혼여부, 월경간격의 5 가지 변인이었으며, 이는 연 구대상자 월경곤란증의 $27.3 \%$ 를 설명하였고. 그 중 D형 성격 유형의 설명력은 $17.7 \%$ 로 월경곤란증 관련 가장 강력한 영향 요인으로 나타났다.

결론적으로, 기존 월경곤란증 관련 연구가 주로 월경 불편 감 보완 대체 중재효과에 대한 연구가 많고, 인간 개인특성에 대한 접근이 많지 않음을 감안했을 때, 본 연구는 인간 개인의 특성에 중점을 두어 간호전략적으로 여성의 월경곤란증 관련 성격유형에 대한 분석과 분류를 통한 접근의 필요성을 밝혔다 는데 의의가 있다. 이는 향후 월경곤란증 감소화 프로그램 개 발과 관련한 기초자료로 활용될 수 있다.

\section{참고문헌}

Bae SH, Park JH, Oh EG. A Comparison of the health status and health promoting behaviors between type $\mathrm{D}$ personality and non-type D personality in middle aged women. Korean J Women Health Nurs 2011;17(4):337-45.

Cheon SH, Choi MS, Lee SJ. The risk behaviors to increase exposure toward endocrine disrupting chemicals, depression and physical symptom among university students. J Korean Soc Living Environ Sys 2016;23(5):677-86.

Denollet J. DS14: Standard assessment of negative affectivity, social inhibition, and type D personality. Psychosom Med 2005;67 (1):89-97.

Denollet J, Van Heck GL. Psychological risk factors in heart disease: what type D personality is (not) about. J Psychosom Res 2001;51(3):465-8.

Faul F, Erdfelder E, Buchner A, Lang AG. Statistical power analyses using G* Power 3.1: Tests for correlation and regression analyses. Behav Res Methods 2009;41(4): 1149-60.

Guvenc G, Kilic A, Akyuz A, Ustunsoz A. Premenstrual syndrome and attitudes toward menstruation in a sample of nursing students. J Psychosom Obstet Gynaecol 2012;33 (3) : $106-11$.

Han JH, Kim S, Kim SH, Lee SK. Relationships among menstrual attitude, premenstrual distress, and premenstrual coping in korean college women. Korean J Women Health Nurs 2017;23(1):11-20.

Hwang JH, Sung MH. Impacts of menstrual attitudes, premenstrual syndrome and stress on burnout among clinical nurses. Korean J Women Health Nurs 2016;22(4):23340. 
Yoon SJ. Influence of Type D Personality, Dietary Assessment and Increase Exposure Toward Endocrine Disrupting Chemicals on the Dysmenorrhea

Jung GS, Oh HM, Choi IR. The influential factors on premenstrual syndrome college female students. JKAIS 2014; $15(5): 3025-36$.

Kim BK, Choi MJ, Kwon YD, Noh JW. Affecting changes of meal habit into stress and depression among north korea juvenile. North Korean Studies Review 2014;18(2):31133.

Kim HK. Impact of pro-environmental behavior on dysmenorrhea. J Korean Acad Nurs 2011;41(2):236-44.

Kim HY, Cho MS, Lee HS. Development and validation of mini dietary assesment index for koreans. J Nutr Health 2003;36(1):83-92.

Kim JE. Comprehensive understanding of perimenstrual discomfort: A triangulation of methods and perspectives. Unpublished doctoral dissertation, Seoul National University, Seoul. 1995.

Kim JH, Park MK, Oh MR. Meta-analysis of complementary and alternative intervention on menstrual distress. Korean J Women Health Nurs 2013;19(1):23-35.

Kim MR, Kim HC. Recognition, Information acquisition behavior, knowledge, behaviors to decrease exposure and endocrine disruptors among middle and high school students. Journal of The Korean Association of Practical Arts Education 2009;21(3):123-42.

Kim SR, Kim HY, Kang JH. Effects of type D personality on compassion fatigue, burnout, compassion satisfaction, and job stress in clinical nurses. J Korean Acad Nurs Adm 2014;20(3):272-80.

Kim YI, Lee EH, Jeon GE, Choi SJ. A study on coping styles for dysmenorrhea and affecting factors in middle school students. J Korean Acad Community Health Nurs 2013; $24(3): 264-72$.

Lee GH, Jung HS, Lee DW, Park KH. Life style, stress, menstrual history and dietary habits related to primary dysmenorrhea in a college women. J Health Info Stat
2010;35(1):29-39.

Lim HE, Lee MS, Ko YH, Park YM, Joe SH, Kim YK et al. Assessment of the type D personality construct in the Korean population: a validation study of the Korean DS14. J Korean Med Sci 2011;26(1):116-23.

Mendola P, Messer LC, Rappazzo K. Science linking environmental contaminant exposures with fertility and reproductive health impacts in the adult female. Fertil Steril 2008; $89(2): 81-94$.

Moos RH. The development of a menstrual distress questionnaire. Psychosom Med 1968;30 (6):853-67.

National Institute of Korean Language (NIKL). Korean Dictionary, 2017a [cited 2017 Oct 15]. Available from: URL: http://krdic.naver.com/detail.nhn?docid=29240700.

National Institute of Korean Language (NIKL). Korean Dictionary, 2017b [cited 2017 Oct 15]. Available from: URL: http://krdic.naver.com/detail.nhn?docid=21324700.

Park JM, Suh SR, Kim KY, Kim HJ. Female workers' attitudes toward menstruation, premenstrual discomfort and coping method. J Korean Soc Matern Child Health 2012;16(1): 100-12.

Son HM. Verification for the validity and reliability of the type D scale-14D. J Korean Acad Fundam Nurs 2008; $15(3): 312-20$.

Son YJ, You M, Song EK. Influence of type D personality on health-related quality of life among korean patients with end-stage renal disease. Int J Nurs Pract 2012;18 (3) :260-7.

Women's Health Nursing Academic Research Institutes (WHNAR). Women's health nursing I, SOOMOONSA, Paju, 2012;334-6.

Yoon SJ, Kim HK, Han JY. Influencing factors of depression in drugs exposure pregnant women. J Korean Soc Matern Child Health 2014;18(2):273-85. 